Document downloaded from:

http://hdl.handle.net/10251/136474

This paper must be cited as:

Parker, M.; Walker, SD.; Llorente, R.; Morant, M.; Beltrán, M.; Möllers, I.; Jäger, D.... (2010). Radio-over-fibre technologies arising from the Building the future Optical Network in Europe (BONE) project. IET Optoelectronics. 4(6):247-259. https://doi.org/10.1049/iet-opt.2009.0062

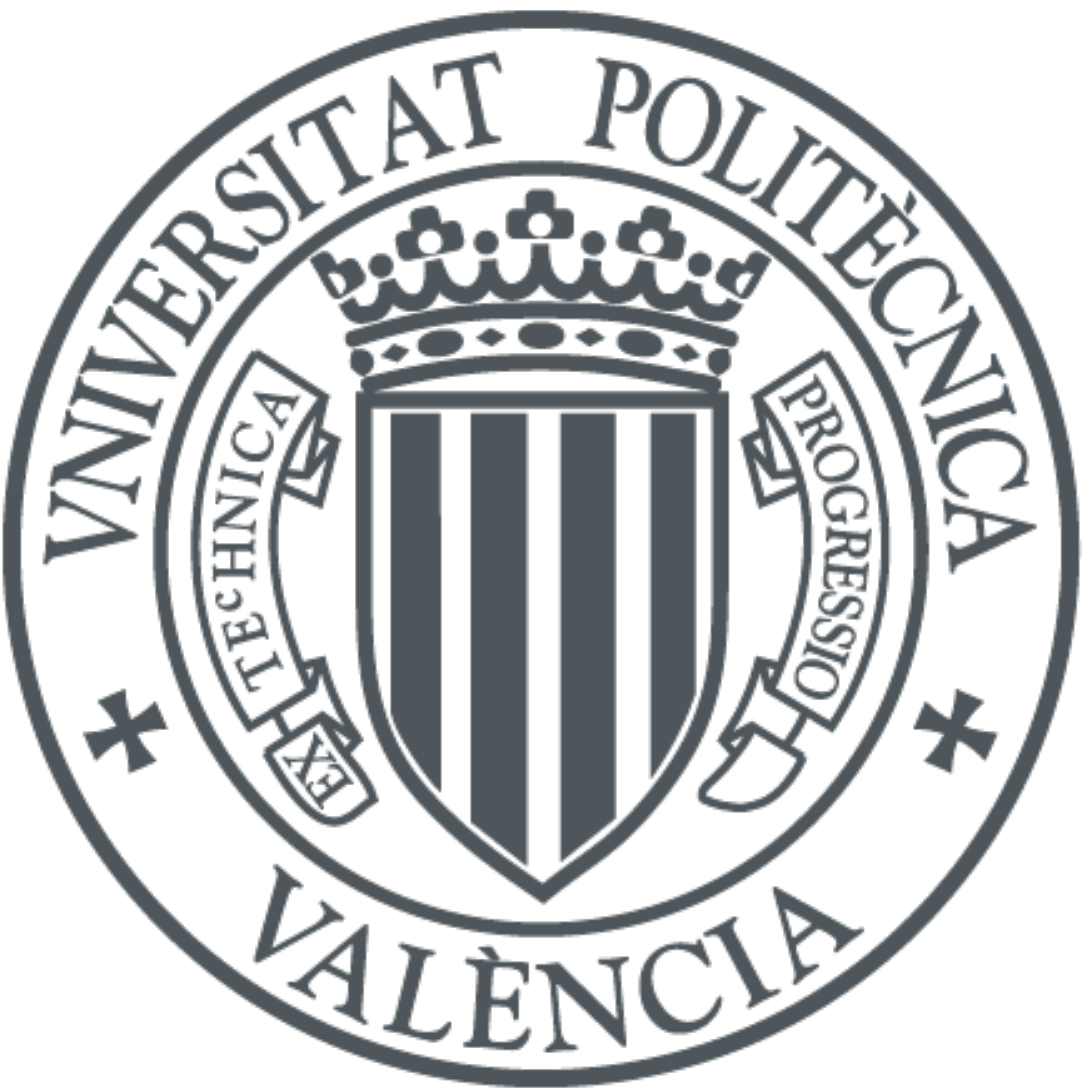

The final publication is available at

https://doi.org/10.1049/iet-opt.2009.0062

Copyright Institution of Electrical Engineers

Additional Information 


\title{
Radio-over fibre technologies arising from the Building the future Optical Network in Europe (BONE) project
}

\author{
Michael Parker ${ }^{1}$, Stuart D. Walker ${ }^{1}$, Roberto Llorente ${ }^{2}$, Maria Morant ${ }^{2}$, Marta Beltrán ${ }^{2}$, \\ Ingo Möllers ${ }^{3}$, Dieter Jäger ${ }^{3}$, Carmen Vázquez ${ }^{4}$, David Montero ${ }^{4}$, I. Librán ${ }^{4}$, Spiros Mikroulis ${ }^{5,6}$, \\ Sotiris Karabetsos ${ }^{5}$, Adonis Bogris ${ }^{6}$
}

${ }^{1}$ School of Electronics Engineering and Computer Sciences, University of Essex, Wivenhoe Park, Colchester, CO4 3SQ,UK, email: mcpark@essex.ac.uk; stuwal@essex.ac.uk

${ }^{2}$ Valencia Nanophotonics Technology Center, Universidad Politécnica de Valencia, Camino de Vera s/n, 46022 Valencia, Spain,email: rllorent@dcom.upv.es; mmorant@ntc.upv.es; mbeltran@ntc.upv.es

${ }^{3}$ Zentrum für Halbleitertechnik und Optoelektronik, Universität Duisburg-Essen, Lotharstr. 55, Gebäude LT, D-47057 Duisburg, Germany, email: ingo.moellers@uni-due.de,dieter.jaeger@uni-due.de

${ }^{4}$ Electronics Technology Department, Universidad Carlos III de Madrid, Escuela Politécnica Superior, Av. Universidad 30, 28911 Leganés, Madrid, Spain,email: cvazquez@ing.uc3m.es,dsmontero@ing.uc3m.es ${ }^{5}$ RDTL Laboratory, Department of Electronics, Technological Educational Institute (TEI) of Athens, Athens, Greece,email: spirosm@di.uoa.gr

${ }^{6}$ Department of Informatics and Telecommunications, University of Athens, Illissia, 15784, Athens, Greece

\begin{abstract}
This paper describes a wide range of salient radio-over-fibre (RoF) system issues. Impulse radio (IR) and multi-band (MB) ultra-wideband (UWB) signal distribution, over both single-mode fibre (SMF) and multimode fibre (MMF) implementations are considered. Carrier frequencies ranging from 3.1-10.6 GHz, up to $60 \mathrm{GHz}$ are featured, and the use of microring laser transmitters is discussed. A cost-performance comparative analysis of competing distributed antenna system (DAS) topologies is presented, and a theoretical approach to understanding the factors underlying radio-over-MMF performance for within-building applications is discussed. Finally, techniques to minimise thermal impacts on performance are described and novel energyefficient schemes introduced. Overall, this paper provides a snap-shot of research being undertaken by European institutes involved in the Building the future Optical Network in Europe (BONE) project.
\end{abstract}




\section{Introduction}

Research into next-generation access (NGA) network technology is being driven by Nielsen's Law with internet-access bandwidths doubling approximately every 21 months [1]. End-user access bandwidths could reach $1 \mathrm{~Gb} / \mathrm{s}$ by 2015 , and $10 \mathrm{~Gb} / \mathrm{s}$ by 2020 . Emerging themes in next-generation access (NGA) research include: convergence technologies, green telecoms, and soft photonics, whilst seamless wireline-wireless convergence is addressed by radio-over-fibre (RoF) technologies. Photonics will transport gigabit data across the access network, but the final link to the end-user (measured in distances of metres, rather than km's) could well be wireless, with portable/mobile devices converging with photonics. RoF technologies can address the predicted multi-Gb/s data wave, whilst conforming to reduced carbon footprints (i.e. green telecoms). Soft photonics is also an increasingly important aspect to telecoms, describing the use of ever more powerful digital signal processing (DSP) electronics, particularly within receiver equipment, to achieve higher performance (e.g. high data rates) via the use of intelligent and adaptive systems. NGA networks will provide a common resource, with passive optical networks (PONs) supplying bandwidth to buildings, and offering optical backhaul for remote antenna units (RAUs) located at base stations (BSs). Seamless use of portable devices, indoors, outdoors and on the move (in transport) will be possible, with networks dynamically managing the performance of the mobile devices.

The paper is arranged as follows: Section 2 discusses the development of lower carrier frequency (3.1 to 10.6 $\mathrm{GHz}$ ) RoF technologies using standard single mode fibre (SMF) to distribute ultra wideband (UWB) signals. Section 3 presents results on more advanced RoF technologies, including the use of higher carrier frequencies $(60 \mathrm{GHz})$ to distribute impulse radio (IR) UWB signals, and the use of microring laser transmitters. Energy efficiency gains for RoF systems via software-defined antennas (cloning and holographic technologies) are also discussed. Section 4 presents radio-over-multimode fibre (RoMMF) theory for within-building applications, a cost-performance comparative analysis of different distributed antenna systems (DAS's), and the distribution of IR and multi-band (MB) UWB over RoMMF systems. Section 5 considers RoF impairment mitigation, and conclusions are given in section 6 .

\subsection{1 - 10.6 GHz RoF technologies}

UWB is a radio technology for replacing cables within picocells, with high definition (HD) video and audio [2] a typical candidate application. UWB radio offers: low self-interference, low interception probability and tolerance to multi-path fading, and comes in two main implementations: multi-band orthogonal frequency 
division multiplexing (MB-OFDM) and impulse radio (IR). The ECMA standard [3] uses MB-OFDM in 528 MHz individual sub-bands, whilst the IR implementation employs short pulses to fill a desired bandwidth. MBOFDM generally shows superior performance to the IR approach in terms of multi-path fading and intersymbol interference (ISI) tolerance. Currently, UWB uses the 3.1 to $10.6 \mathrm{GHz}$ band [3-5]; with bandwidth significantly wider than $50 \mathrm{MHz}$ as in ETSI regulations [6].

\subsection{RoF distribution of UWB signals in standard single-mode fibre}

UWB RoF distribution over SMF has been proposed in [7] for RoF high-definition audio-video distribution in optical access networks, e.g. in fibre-to-the-home (FTTH) networks. Here, the performance of both MB-OFDM and IR UWB implementations bearing $1.25 \mathrm{~Gb} / \mathrm{s}$ is analysed and experimentally compared. In Fig. 1, the UWB signal is transmitted along different SMF links, ranging from 25 to $60 \mathrm{~km}$, with $-2 \mathrm{dBm}$ average optical power after modulation and before transmission at point (2). The UWB signal modulates a $20 \mathrm{GHz}$ bandwidth quadrature-biased Mach-Zehnder electro-optical modulator (MZ-EOM) and is transmitted as shown. Inline amplification (where necessary) is realized using a $23 \mathrm{~dB}$ gain, $4 \mathrm{~dB}$ noise figure erbium-doped fibre amplifier (EDFA). The receiver also includes a $4.5 \mathrm{~dB}$ noise figure, $19 \mathrm{dBm}$ saturation power EDFA to evaluate the link budget. After fibre transmission, the signals are optically bandpass filtered $(0.8 \mathrm{~nm} @-0.5 \mathrm{~dB}$ bandwidth $)$ and detected by a PIN photodiode $(0.65 \mathrm{~A} / \mathrm{W}, 50 \mathrm{GHz}$ bandwidth). Performance is evaluated with the received optical power ranging from 0 to $10 \mathrm{dBm}$ at the photodiode at point (3).

The OFDM-UWB transmitter consists of three OFDM channels with 128 QPSK-modulated carriers, with an aggregated $1.25 \mathrm{~Gb} / \mathrm{s}$ bit-rate. As shown, an arbitrary waveform generator (AWG6030) with 1.25 Gsamples/s produces three OFDM channels with the middle segment used for performance study. The OFDM-UWB spectrum is shown in Fig. 1(a), with $3.51 \mathrm{GHz} @-10 \mathrm{~dB}$ bandwidth. In the IR-UWB transmitter a $10 \mathrm{GHz}$ Gaussian pulse $\left(\mathrm{T}_{\mathrm{fwhm}}=2.8 \mathrm{ps}\right)$ train is generated by a $1.25 \mathrm{GHz}$ mode-locked laser gated by a MZ-EOM with 1.25 Gb/s PRBS data. After detection and shaping to monopulses with $\mathrm{T}_{\mathrm{fwhm}}=283 \mathrm{ps}$, the signal is up-converted to $\mathrm{f}_{\mathrm{LO}}=6.6 \mathrm{GHz}$ for fibre transmission. As shown in Fig. 1(b), the IR-UWB signal had $3.2 \mathrm{GHz}$ bandwidth at -10 $\mathrm{dBm}$, following the FCC spectral mask [4]. Subsequently, the detected signal was converted to baseband and sampled by an HP83486A module (20 GHz bandwidth). In the OFDM-UWB case, the channel under study is equalized from pilot information, demodulated, and the error vector magnitude (EVM) measured. The bit-error ratio $(\mathrm{BER})$ is calculated as $\mathrm{BER}=\operatorname{erfc}(\sqrt{2} / \mathrm{EVM})$ for a QPSK OFDM signal [8]. In the IR-UWB cases, the 
monopulses are demodulated, low-pass filtered and the Q-factor measured. Assuming Gaussian noise, the BER is given by $\mathrm{BER}=\operatorname{erfc}(Q / \sqrt{2})$. The measurements have been done in back-to-back (B2B), $25 \mathrm{~km} \mathrm{SMF}$ without inline amplification, and 50 and $60 \mathrm{~km}$ SMF with inline amplification configurations. Fig. 2 shows the performance of OFDM-UWB and IR-UWB in terms of BER for different received powers, measured at point (4) in Fig. 1. The experimental results demonstrate the feasibility of distributing $1.25 \mathrm{~Gb} / \mathrm{s}$ UWB signals, whilst achieving BER $<10^{-9}$ operation at $50 \mathrm{~km}$ with both IR-UWB and OFDM-UWB implementations. Fig. 2 shows that the IR-UWB technique exhibits performance degradation in comparison with OFDM-UWB. In addition, it can be observed that OFDM-UWB degrades quickly with fibre length, due to the carrier suppression effect [9], whilst the OSNR degradation is due to chromatic dispersion [10].

\section{Next-generation RoF techniques}

\section{1 $60 \mathrm{GHz}$ impulse-radio UWB technologies}

The $6 \mathrm{GHz}$ UWB unlicensed low band is not available worldwide due to coexistence concerns [11]. Outside the United States, available bandwidth is $1.5 \mathrm{GHz}$ which only supports hundreds of Mbit/s data-rates. However, the $60 \mathrm{GHz}$ band offers much greater opportunities.

Fig. 3 shows photonic generation of $57 \mathrm{GHz}$ IR-UWB monocycles at $1.244 \mathrm{~Gb} / \mathrm{s}$ with transmission over $100 \mathrm{~m}$ of SMF [12]. The approach uses optical UWB signals frequency up-conversion in the MZ-EOM nonlinear regime. Baseband monocycles are generated as RZ fixed-sequence OOK modulated (1011100110100100) data at $1.244 \mathrm{~Gb} / \mathrm{s}$. The generation is based on data modulation of Gaussian optical pulses and further monocycle shaping employing a differential photoreceiver and delay. Optical pulses from an actively mode-locked laser are modulated with the data in a MZ-EOM and time-stretched in $10 \mathrm{~km}$ SMF to adjust the pulse width as required, whilst a commercial photoreceiver (Teleoptix, DualPIN-DTLIA Rx) and suitable delay are employed to shape an appropriate UWB monocycle spectral envelope exhibiting a $3.8 \mathrm{GHz}$ bandwidth, maximising $1.244 \mathrm{~Gb} / \mathrm{s}$ spectral efficiency. These baseband monocycles are subsequently converted into the optical domain via external modulation of a MZ-EOM. Fig. 4(a) shows the optical monocycles at point (1) in Fig. 3.

The optical amplifier sets the $60 \mathrm{GHz}$ band UWB signal at point (2) in Fig. 3 to $-41.3 \mathrm{dBm} / \mathrm{MHz}$. A lowfrequency $14.25 \mathrm{GHz}$ local oscillator (LO) multiplied by 2 is applied to the MZ-EOM employed for upconversion, resulting in UWB monocycles at $57 \mathrm{GHz}$ after photodetection. Fig. 4(b) shows the RF spectrum of 
the UWB signal in the $60 \mathrm{GHz}$ band to be radiated at point (2). Finally, the $57 \mathrm{GHz}$ generated UWB monocycles are demodulated directly (again, with no air transmission) employing conventional electrical homodyne detection to verify their appropriate operation. Fig. 4(c) shows the eye diagram of the demodulated monocycles at point (3). Good quality (Q-factor about 7) is achieved with no performance degradation after $100 \mathrm{~m}$ of SMF transmission.

\subsection{Microring lasers for RoF Applications}

Integrated, low-cost, tunable optical transmitters are likely to be an important component of NGA networks based on heterogeneous (i.e. hybrid optical/wireless) technologies. We have evaluated semiconductor microring lasers as a novel optical component for low-cost, integrated, direct modulated transmitters in current and emerging RoF systems. Assessment employs a dynamic multimode laser model [13]. Microring lasers have previously been used in conventional optical networks [13]-[16], where InGaAsP/InP prototypes [17] demonstrated direct modulation ability of $7 \mathrm{~Gb} / \mathrm{s}$ in back-to-back transmission [16]. $10 \mathrm{~Gb} / \mathrm{s}$ operation has recently been predicted when combined with $10 \mathrm{~km}$ SMF transmission, where the internal feedback which is provided from the bus waveguide reflectivity [13] promotes transient chirp suppression and enables multiwavelength (i.e. WDM) operation.

In the following numerical evaluations, UWB signals have been produced utilizing MB-OFDM in the 3.1-10.6 GHz range. The impact of the transmitter's nonlinearity and intensity noise is rendered in constellation diagrams and EVM calculations, respectively. Tunable WDM operation has also been investigated and observed through phase-shifted feedback from the bus waveguide. Active phase sections (Fig. 5) can be integrated into the bus waveguide for phase tuning without altering the feedback strength [18]. Calculations show that phase alterations of $\Delta \varphi=\pi / 2, \Delta \varphi=0$ and $\Delta \varphi=2 \pi / 3$ shift the laser's peak wavelength between adjacent modes: $\lambda_{1}=1550 \mathrm{~nm}$, $\lambda_{2}=1552.2 \mathrm{~nm}$ and $\lambda_{3}=1554.4 \mathrm{~nm}$, respectively. The numerical results depicted a minimum EVM performance of the order of $5 \%$ for all MB-OFDM bands when the modulation ratio, defined as the ratio of the peak OFDM modulation current to the laser's bias current (i.e., $\mathrm{m}_{\mathrm{r}}=\mathrm{I}_{\mathrm{mod}} / \mathrm{I}_{\mathrm{b}}$ ), is appropriately optimised. Fig. 6(a) shows EVM calculations as a function of the modulation ratio $\mathrm{m}_{\mathrm{r}}$, for the MB-OFDM sub-bands 1,7 and 13 operating at $\lambda_{2}=1552.2 \mathrm{~nm}$. For relatively low modulation ratios (i.e., $\mathrm{m}_{\mathrm{r}}<0.15$ ) it can be seen that the EVM increases due to the increased effect of the laser's intensity noise. For somewhat greater modulation ratios (i.e. $m_{r}>0.30$ ) the EVM increases due to the greater affect of the laser's nonlinearity - a behaviour that becomes more intense as the frequency bands approach the laser's resonance frequency. Fig. 6(b) also depicts EVM calculations as a 
function of the modulation ratio $\mathrm{m}_{\mathrm{r}}$ for the MB-OFDM sub-band 13 at different wavelengths: $\lambda_{1}=1550 \mathrm{~nm}$, $\lambda_{2}=1552.2 \mathrm{~nm}$, and $\lambda_{3}=1554.4 \mathrm{~nm}$. It can be seen that tunable operation presents no significant penalty on the respective EVM performances.

\subsection{Software-defined RoF systems for improved energy efficiency operation}

Operating RoF systems in the lower $\mathrm{GHz}$ regions (i.e. up to $3.5 \mathrm{GHz}$ ) frequently requires energy-inefficient multi-level coding formats in order to conserve bandwidth. In contrast, band-spreading using OFDM (e.g. in the scalable version of 802.16) can be energy-efficient, whilst use of the $60 \mathrm{GHz}$ frequency region can feature power-efficient BPSK modulation. At $60 \mathrm{GHz}$, the free-space path loss (FSPL) formula, equation (1), mitigates against long spans at mm-wave frequencies:

$$
\text { Pathloss }[d B]=20 \log _{10}(f[M H z])+20 \log _{10}(d[k m])+32.44
$$

However, if a mesh-distribution topology (using fibre fed hubs) with <km bound dimension is chosen, many of the difficulties of $60 \mathrm{GHz}$ wireless are reduced. Atmospheric oxygen contributes a loss of about $16 \mathrm{~dB} / \mathrm{km}$, whereas the heaviest rain fall (e.g. $100 \mathrm{~mm} / \mathrm{hr}$ ) contributes an attenuation of about $30 \mathrm{~dB} / \mathrm{km}$. Choosing a $100 \mathrm{~m}$ distance reduces these penalties to modest levels, leaving $108 \mathrm{~dB}$ FSPL. For $20 \mathrm{~dB}$ signal-to-noise ratio (SNR) and $1 \mathrm{GHz}$ bandwidth, the minimum received power (at $290 \mathrm{~K} ; 1 \mathrm{~dB}$ noise figure) required is $-63 \mathrm{dBm}$. Assuming $0 \mathrm{dBm}$ transmitter power, this leaves $45 \mathrm{~dB}$ total antenna gain requirement or $22.5 \mathrm{~dB}$ each. Additional link gain can be won by the use of antenna arrays (i.e. cloned transmitters and receivers) with additional advantages due to the holographic redundancy of such a system. Software control of the cloned antennas also minimises power dissipation [19]. Figures 7(a)-(d) show a basic subset of the multipleinput/multiple-output (MIMO) configuration. The transmitter and receiver elements are cloned as required; not being switched on if the link budget is adequate. For respective $N \times N$ transmitter and receiver arrays, the cloning advantage $A$ is given by:

$$
A[d B]=80 \log _{10}(N)
$$

Initial proof-of-principle results for $2 \times 2$ transmitter and receiver arrays have shown an overall $22 \mathrm{~dB}$ reciprocity advantage as compared to the $24 \mathrm{~dB}$ theoretically expected from equation (2), for $N=2$. Equation (2) also shows that for an $N=3$ system, with $0 \mathrm{dBm}$ transmitter output, standard patch antennas ( $9 \mathrm{dBi}$ gain) at the transmitter and receiver, and $4.6 \mathrm{~dB}$ atmospheric penalties for a $100 \mathrm{~m}$ link, would allow $6.6 \mathrm{~dB}$ margin on the assumed 20dB SNR. Even $1 \mathrm{~km}$ spans are possible using the cloning advantage, e.g. with $N=10$ we achieve a $3 \mathrm{~dB}$ 
margin (all other parameters the same). Finally, at $60 \mathrm{GHz}$, the free-space wavelength is $5 \mathrm{~mm}$, so that a $10 \times 10$ array will be approximately just $50 \mathrm{~mm}$ square.

\section{RoF using multi-mode fibre (MMF)}

RoF in combination with multimode fibres (RoMMF) can be deployed within homes and office buildings for baseband digital data transmission supporting $3.5 \mathrm{GHz}$ wireless signals. The large core diameter of MMF fibres (typically $50 \mu \mathrm{m}$ or $62.5 \mu \mathrm{m}$ ) offers easier installation in within-building environments compared to SMF [20]. Several studies have reported on UWB transmission for in-building applications, including wall [21] and multipath effects [22]. We note that MMF is also widely used in within-building fibre installations for baseband data transmission systems at far more than $10 \mathrm{Gbit} / \mathrm{s}$.

\subsection{Applications for within-building systems}

MMF has attracted much attention for high speed digital data rates such as those required by GbE applications [23] or those combining the broadband capability with WDM transmission [24]. Bandwidth improvement techniques include microwave signals transmitted over MMF links [25,26], mode group diversity multiplexing [27], subcarrier multiplexing (SCM) [28] and wavelength division multiplexing (WDM). In order to maximise performance in MMF, accurate models to describe the signal propagation through multimode fibres are required. For the analysis of signal propagation through MMF fibres, a closed-form analytic expression is presented in [29]. This expression can be defined as the relation between the power of the signal emitted by the optical source, which is modulated in frequency, and the power of the signal received at the optical detector and can be written as:

$$
H(\Omega)=\sqrt{1+\alpha^{2}} \cdot e^{\frac{1}{2}\left(\frac{\beta_{o}^{2} \cdot z \cdot \Omega}{\sigma_{c}}\right)^{2}} \cdot \cos \left(\frac{\beta_{o}^{2} \cdot z \cdot \Omega^{2}}{2}+\arctan (\alpha)\right) \cdot \sum_{v=1}^{M} 2 v \cdot\left(C_{v v}+G_{v v}\right) \cdot e^{-2 \alpha_{v} z} \cdot e^{j \Omega \tau_{v} z}
$$

where $\beta_{o}{ }^{2}$ is the second derivative of the propagation constant (which is assumed to be equal for all the modes guided in the fibre), $\sigma_{c}$ is the source RMS coherence time (directly related to the source linewidth $W$ in $\mathrm{Hz}$ ), $v$ is the mode group, $\alpha_{v}$ and $\tau_{v}$ are the modal attenuation and the group delay associate to a mode group $v$, respectively, and $C_{v v}$ and $G_{v v}$ are coefficients which are related to the light injection and mode coupling correlation in the multimode fibre, respectively. Equation (3) as reported in [29] can be considered as the product of three terms. From the left to the right, the first term is a low-pass frequency response which depends on the first order chromatic dispersion parameter $\beta_{o}{ }^{2}$ and the parameter $\sigma_{c}$. The second term is related to the 
carrier suppression effect due to the phase offset between the upper and lower modulation sidebands. Finally, the third term represents a microwave photonic transversal filtering effect, in which each sample corresponds to a different mode group $v$ carried by the fibre. This last term indicates that the periodic frequency response of transversal filters could permit broadband RF transmissions far from baseband, with broadband RoF transmission in the microwave and millimetre wave regions in short $(2-5 \mathrm{~km})$ and middle $(10 \mathrm{~km})$ reach distances possible.

Fig.8(a) shows the theoretical simulation of a MMF link frequency response for different lengths $(L=3050 \mathrm{~m}, L=$ 6100m and $L=9150 \mathrm{~m}$ ), when the GRIN exponent of the fibre is $\alpha=2$ for two situations: considering or not the effects of mode coupling (MC) and differential mode attenuation (DMA) [29]. It can be seen that higher order resonances far from baseband are slightly displaced over the frequency spectrum, with changes in attenuation when MC and DMA are considered or not.

An important aspect not previously considered and highlighted by our model, is the great dependence of the broadband RoF transmission in the microwave and millimetre wave regions far from baseband on the GRIN profile fibre tolerances. Instead of simulating a $10 \%$ graded index exponent deviation as in [29], we have simulated 1\% GRIN exponent deviations. Fig. 8(b) and Fig. 8(c) show the frequency response of the MMF link for $L=2 \mathrm{~km}$ and $L=3 \mathrm{~km}$, respectively, depending on the GRIN exponent, $\alpha$, of the fibre. Significant displacements of the higher order resonances over the frequency spectrum can be achieved with regards to this parameter. For example, from Fig. 8(b), an increase of $\alpha^{\prime}=\alpha+0.02$ produces a change of the first order resonance up to $2.8 \mathrm{GHz}$. Both figures show that higher order resonances far from baseband change the $-3 \mathrm{~dB}$ bandwidth according to the $\alpha$ parameter.

\subsection{Applications for in-building distributed antenna systems (DAS) systems}

In-building coax or fibre-fed distributed antenna systems (DAS) can be used to create hybrid fixed-wireless networks with a large number of small picocells. The use of optical fibres [30] and even MMF can be beneficial for serving multiple signals of different standards within the system [20,31,32]. DAS systems also allow DSP functionalities to be shifted from the base station to the central station (CS), to enable the use of simple base stations containing only optoelectronic devices, an integrated antenna, and, if desired, analogue signal amplification and filtering. With the CS acting as a multiple service and network management system connected to the access network via FTTH for NGA services, RoMMF-DAS technology offers the physical infrastructure 
to create a fusion and convergence of nearly all wireless communications within office and home buildings. A cost and performance analysis for commercially available components comparing different fibre and coaxial radio equipment is listed in Table 1. Four DAS infrastructures (coax, SMF, MMF, and POF) are compared with respect to installation effort, CAPEX, system dynamic range (SDR) and attenuation. RoMMF transmission may have cost and performance advantages over coax, in particular for transmission lengths of more than $200 \mathrm{~m}$, whilst even POF-based solutions can be sufficient for short RoF transmission links $(<50 \mathrm{~m})$. Due to the ability to transmit different wireless standards transparently over MMF up to (carrier) frequencies of $10 \mathrm{GHz}$, we conclude that such systems can particularly address the following applications:

- $\quad$ Access (GSM900/1800, UMTS/LTE, WiMAX)

- $\quad$ LAN (WLAN, DPRS)

- $\quad$ PAN (Bluetooth).

- $\quad$ Sensor, Telemetry, etc. (ZigBee, RFID, DVB-H/T)

Recently, the use of a passive, low-power and low-cost optoelectronic WDM transceiver, respectively, containing a modulator (modulation wavelength $790 \mathrm{~nm}$, quasi-transparent at $850 \mathrm{~nm}$ ) that has been superintegrated with a PD $(850 \mathrm{~nm})$ for single-fiber full-duplex bidirectional RoMMF transmission at the BS has been demonstrated as shown in Fig. 9(a). This device is, to our knowledge, the first full-duplex vertically integrated MMF transceiver capable of FDD transmission for frequencies beyond 5 GHz. Fig. 9(b) shows a block diagram of the RoF base station containing the passive bidirectional full-duplex reflective electro-optic transceiver as a key OE/EO -element for low-power consumption (0V bias for modulator and PD) base stations in DAS systems. The transceiver at the BS is connected via one MMF or POF. A radio-frequency (RF) circuit containing filters builds the connection to the wireless link using two antennas, whilst the BS is fully frequency division duplex (FDD), with full-duplex transmission using two carrier frequencies simultaneously, making it compatible for novel applications, e.g. LTE. EVM measurements have shown that multiple-standard transmission (GSM, DPRS, UMTS, WLAN 802.11b) can be achieved using the modulator for uplink transmission with multimode glass (more than $200 \mathrm{~m}$ ) and perfluorinated POF (50 m), respectively [34].

The use of this novel transceiver in RoF DAS systems can reduce the complexity of RoF systems. Active components (e.g. lasers, VCSELs) need only be installed inside the CS, whilst only one fibre need be installed for each BS, which additionally reduces complexity and cost of the system. Due to the capability of transparent 
transmission of multi-standard wireless signals, the proposed transmission system offers convergence capability between fixed-optical and future wireless communication systems.

\subsection{RoMMF distribution of UWB signals}

The transmission of both MB-OFDM and IR UWB implementations providing similar spectral efficiency (around $0.38 \mathrm{bit} / \mathrm{s} / \mathrm{Hz}$ ) is also possible via RoMMF for indoor applications [35]. Here we consider a MMF with $50 \mu \mathrm{m}$ core and $300 \mathrm{~m}$ length. This distance is in the range of indoor applications as it covers most of the connections in office networks. Fig. 10 shows the set-up implemented to evaluate the performance of the RoMMF distribution of OFDM and IR UWB. The UWB signal at point (1) in Fig. 10 is externally modulated with a CW optical carrier at $1555.75 \mathrm{~nm}$ by a MZ-EOM $\left(\mathrm{V} \pi=1.46 \mathrm{~V}_{\mathrm{DC}}\right)$. In this setup a variable optical attenuator is employed before the MZ-EOM to adjust the power launched into the fibre by adjusting the power at point (2) in Fig. 10 (henceforth referred to as P2) emulating the central office. The modulated signal is transmitted over MMF and the optical power injected into the fibre at point P3 is adjusted with a second attenuator in order to analyze the link budget. After fibre transmission, the signal is photo-detected with a $7 \mathrm{GHz}$ PIN PD with an integrated transimpedance amplifier (TIA). At this point, the PSD of the photo-detected signal is adjusted with an electrical amplifier $(26 \mathrm{~dB}$ gain and $5 \mathrm{~dB}$ noise figure) followed by a variable electrical attenuator to accomplish at point (4) the UWB spectral mask defined in current regulation with a maximum PSD of $-41.3 \mathrm{dBm} / \mathrm{MHz}$ [3-5]. Finally, the signals are demodulated and their performance evaluated. The OFDM UWB signal comprises 3 channels of $528 \mathrm{MHz}$ each bearing $200 \mathrm{Mb} / \mathrm{s}$ with QPSK modulation, generated with Wisair DV9110 standard transmitters [3]. Each UWB transmitter is located at frequency band \#1, \#2 and \#3 respectively from UWB band group \#1, performing a non-hopping time frequency code (TFC5, TFC6 and TFC7). This provides an aggregated bit-rate of $600 \mathrm{Mb} / \mathrm{s}$ and $0.378 \mathrm{bit} / \mathrm{s} / \mathrm{Hz}$ spectral efficiency (10 dB frequency range of $3.168-4.752 \mathrm{GHz}$ ). The maximum PSD of the generated OFDM-UWB signal is $42 \mathrm{dBm} / \mathrm{MHz}$. The spectrum of the OFDM-UWB generated signal is shown in Fig. 11(a), which has been measured at P1 in Fig. 10 by a digital sampling analyzer (DSA) (Agilent 80000B).

The IR-UWB signal comprises baseband monocycles up-converted in frequency to occupy the same frequency range as the OFDM UWB signal. Baseband monocycles are generated as proposed in [12]. In the experiment, RZ fixed-sequence OOK modulated data is generated at $622 \mathrm{Mb} / \mathrm{s}$. Pulse width is adjusted with $10 \mathrm{~km} \mathrm{SMF}$ and proper delay to shape an adequate UWB monocycle spectral envelope exhibiting approximately the same bandwidth as the OFDM case, i.e. $1.584 \mathrm{GHz}(3 \times 528 \mathrm{MHz})$. 
The generated monocycles, after amplification and low-pass filtering ( $3.3 \mathrm{GHz}$ bandwidth) to remove noise at point (6) in Fig. 10, are shown in Fig. 11(b), where the baseband monocycles are frequency up-converted by an electrical mixer. A LO at $3.168 \mathrm{GHz}$ with $9 \mathrm{dBm}$ power (after amplification and $3.3 \mathrm{GHz}$ low-pass filtering) is employed to perform the up-conversion. The IR UWB signal comprises a unique band from $3.168 \mathrm{GHz}$ to 4.752 $\mathrm{GHz}$, bearing $622 \mathrm{Mb} / \mathrm{s}$ with $0.392 \mathrm{bit} / \mathrm{s} / \mathrm{Hz}$ spectral efficiency, similar to the OFDM case for comparative purposes. The maximum PSD of the generated IR UWB signal at point (1) is $-23 \mathrm{dBm} / \mathrm{MHz}$. In the IR-UWB case, demodulation is performed using a conventional electrical homodyne architecture and the Q-factor is measured in the eye diagram of the demodulated monocycles. The BER performance comparison of both OFDM and IR over MMF for different optical power levels P2 and P3 is shown in Fig. 11(c). From the experimental results, IR UWB requires less optical power launched than its OFDM UWB counterpart. Successful transmission over $300 \mathrm{~m}$ MMF can only be achieved at a launch power of $2 \mathrm{dBm}$ for complete OFDM-UWB, or $3 \mathrm{dBm}$ for IR UWB. In the case discussed here, power fading is stronger at the higher OFDMUWB subcarrier frequencies, as analysed in [10]. The main limitation of this UWB RoF in-building distribution is that the optical power levels needed to feed the fibre are quite high, at about 2 and $3 \mathrm{dBm}$ for OFDM and IR respectively, since power fading is stronger at the higher OFDM-UWB subcarrier frequencies.

\section{Temperature dependencies of RoMMF systems}

In addition to the bandwidth limitation by the intermodal dispersion in MMF, the frequency response of MMF links depends on the launching conditions due to excitation-dependent modal group delays and on mode group coupling $[25,29]$. Therefore, launching conditions, variable link lengths, installation bends, connector offsets or the introduction of any other component along the MMF link makes the MMF frequency response unpredictable under arbitrary operating conditions. Variations in temperature also change some of the optical properties of MMF [36,37], allowing for example, RoMMF systems to be also integrated within a remote fibre-optic sensor network [38] and exposed to considerable temperature gradients. Here, we experimentally investigate the temperature dependence of the bandwidth in a silica RoMMF fibre link as the environmental temperature changes. The measurements are taken from $T=28^{\circ} \mathrm{C}$ (environment) to $T=67^{\circ} \mathrm{C}$. The hysteresis cycle of the measurements has also been evaluated at the environmental temperature. A multimode silica optical fibre link has been implemented to experimentally validate the influence of temperature in the proposed model described by Eq. (3). A Fabry-Perot optical source at 1300nm (Agilent $81655 \mathrm{~A}$ ) modulated up to 20GHz by a Lightwave Component Analyzer (LCA, Agilent 8703B) was used to launch optical power into the fibre. The optical power 
at the end of the fibre was collected by a wide bandwidth InGaAs PIN photodiode and its frequency response analyzed by the LCA. MMF specifications were $62.5 / 125 \mu \mathrm{m}$ (core/cladding fibre diameters), $\mathrm{n}_{\text {core }}=1.4558$ (refractive index in the core center), $\mathrm{n}_{\text {cladding }}=1.4472$ (cladding refractive index), $\Delta=0.0059$ (refractive index contrast between the core center and the cladding), $\mathrm{N}_{1}=1.470$ (material group index), $\varepsilon=-0.0482$ (profile dispersion parameter) and $\alpha_{\mathrm{m}}=0.7 \mathrm{~dB} / \mathrm{km}$ (fibre attenuation). Several temperatures were tested for a $L=3050 \mathrm{~m}$ MMF fibre link at $\lambda=1300 \mathrm{~nm}$ up to $20 \mathrm{GHz}$ with an average factor of Avg=16 for each temperature test measurement. Test equipment was isolated from the heating source, so that only temperature changes relating to the MMF fibre spool were measured. Theoretical frequency responses of the MMF silica fibre link with $L=3050$ m and $L=10 \mathrm{~km}$, respectively, both provided by Eq. (3) and evaluated for different temperatures in which no variations on the higher order resonance frequencies are observed are reported in [39]. Fig. 12(a) shows the experimental measurement of the frequency response, at $T=28^{\circ} \mathrm{C}$ and $T=67^{\circ} \mathrm{C}$, and shows that the frequency spectrum takes its higher and lower values at the same frequencies but with a power offset of up to $5 \mathrm{~dB}$ in case of Fig. 12(a), where an average is applied, whereas Fig. 12(b) shows a maximum deviation of $20 \mathrm{~dB}$ at $4 \mathrm{GHz}$ without averaging factor. Fig. 12(c) shows the hysteresis cycle of the MMF link at $T=28^{\circ} \mathrm{C}$ (environmental temperature) when heating (forwards) up to $70^{\circ} \mathrm{C}$ and, then, cooling (backwards). The maximum hysteresis deviation value is $4 \mathrm{~dB}$ at $3 \mathrm{GHz}$. Fig. $12(\mathrm{~d})$ shows the averaged values of the hysteresis cycle at $T=28^{\circ} \mathrm{C}$. By controlling how the temperature affects the fibre link it is possible to avoid the influence of this parameter over the higher order resonances and, consequently, to increase the bandwidth capability of these RoF broadband transmissions.

\section{Conclusions}

In this paper, the RoF performance of the two main OFDM-UWB and IR-UWB implementations has been compared and analyzed. Experimental results demonstrate the feasibility of distributing $1.25 \mathrm{~Gb} / \mathrm{s}$ UWB signals whilst achieving BER $<10^{-9}$ operation over $50 \mathrm{~km}$ SMF with both IR-UWB and OFDM-UWB implementations. OFDM-UWB degrades quickly with fibre length, due to carrier suppression and OSNR degradation due to chromatic dispersion, whilst the IR-UWB generation technique occupying a higher electrical bandwidth without channelization exhibits performance degradations comparable with OFDM-UWB. Other generation techniques have been presented for next-generation UWB technologies up to $60 \mathrm{GHz}$. A technique based on frequency upconversion of optical UWB signals in a MZ-EOM in nonlinear regime has been presented for generating IR- 
UWB monocycles at $57 \mathrm{GHz}$ and at $1.244 \mathrm{~Gb} / \mathrm{s}$. The generation and further transmission over $100 \mathrm{~m}$ of SMF has been demonstrated with good quality pulses with a Q-factor of around 7.

UWB implementations have also been successfully transmitted over $300 \mathrm{~m}$ of MMF, whilst the application of a distributed antenna system (DAS) for providing wireless access to a within-building network has additionally been discussed, with a comparative study made of the relative merits for the various wireline technologies (coax, SMF, MMF and POF) capable of providing a radio-based signal. Thermal effects on the transmittivity of RoMMF s have been studied, so providing a means to mitigate temperature-based performance degradations.

Overall, we have presented results showing how multi-Gb/s data rates may be accessed on a per-user basis via future RoF-based access networks.

7. Acknowledgement: The work described in this paper was carried out with the support of the EU-FP7 Network of Excellence BONE (Building the future Optical Network in Europe) project.

\section{References}

[1] http://www.ftthcouncil.eu

[2] Duan, C., et al.: 'Transmitting multiple HD video streams over UWB links'. Proc. CCNC'06, Las Vegas, January 2006, pp. 691-695

[3] ECMA-368 International Standard: 'High rate ultra wideband PHY and MAC standard'. December 2008

[4] FCC 02-48: 'Revision of part 15 of the commission's rules regarding ultra-wideband transmission systems'. April 2002

[5] ECC/DEC/(06)04: 'On the harmonised conditions for devices using ultra-wideband (UWB) technology in bands below 10.6 GHz'. March 2006

[6] ETSI EN 302065 V1.1.1 (2008-02): 'Electromagnetic compatibility and Radio spectrum Matters (ERM); Ultra WideBand (UWB) technologies for communication purposes; Harmonized EN covering the essential requirements of article 3.2 of the R\&TTE Directive'. February 2008

[7] Llorente, R., et al.: 'Ultra-wideband radio signals distribution in FTTH networks', IEEE Photonics Technology Letters, 2008, 20, (11), pp. 945-947

[8] Shafik, R. A., Rahman, M.S., and Islam, A.H.M.R.: 'On the extended relationships among EVM, BER and SNR as performance metrics'. Proc. ICECE’06, Bangladesh, Dec. 2006, pp. 408-411 
[9] Schmuck, H.: 'Comparison of optically millimeter-wave system concepts with regard to chromatic dispersion', IEEE Electronic Letters, 31, (21), 1995, pp. 1848-1849

[10] Alves, T., and Cartaxo, A.:' Performance Degradation Due to OFDM-UWB Radio Signal Transmission Along Dispersive Single-Mode Fiber', IEEE Photonic Technology Letters, 21, (3), 2009, pp. 158-160

[11] WiMedia Alliance, Worldwide regulatory status [Online]. Available: http://www.wimedia.org

[12] Beltrán, M., Llorente, R., Sambaraju, R., and Martí, J.: '60 GHz UWB-over-fiber system for in-flight communications'. Proc. IEEE MTT-S International Microwave Symposium, Boston, MA, June 2009, pp.5-8

[13] S. Mikroulis, A. Bogris, and D. Syvridis, "Transient chirp suppression in directly modulated microring lasers” IEEE Photon. Technol. Lett., Vol. 21, no. 6, pp. 395-397, 2009

[14] S. Mikroulis, E. Roditi, D. Syvridis, "Direct modulation properties of $1.55 \mu \mathrm{m}$ InGaAsP/InP microring lasers”, IEEE J. Light. Technol., Vol. 26, pp. 251-256, 2008

[15] A. Bennecer, K. A. Williams, R. V. Penty, I. H. White, M. Hamacher, and H. Heidrich, "Directly Modulated Wavelength-Multiplexed Integrated Microring Laser Array”, IEEE Photon. Technol. Lett., Vol. 20, no. 16 , pp. 1411-1413, 2008

[16] A. Kapsalis, D. Syvridis, U. Troppenz, M. Hamacher, H. Heidrich, “7Gb/s Direct Modulation of Vertically Coupled Microring Lasers”, in Proc. OFC/NFOEC 2008, San Jose, CA, Feb. 24-28, 2008, Paper 1377

[17] IST-II- "Wafer bonding and active passive integration technology and implementation, (STREPWAPITI)', (004073)

[18] A. Argyris, M. Hamacher, K. E. Chlouverakis, A. Bogris, and D. Syvridis, "A photonic integrated device for chaos applications in communications,” Phys. Rev. Lett., vol. 100, p. 194101, May 2008

[19] M.C. Parker, and S.D. Walker, “An Absolute Network Energy Efficiency Metric”, 1st International ICST Workshop on Green Grids (Green Grids 2009), Athens, Greece, September 2009

[20] Koonen, A.M.J., and Garcia, L.M.: 'Radio-over-MMF techniques Part II: Microwave to millimeter-wave systems', IEEE Journal Lightwave Technology, 2008, 26, (15), pp. 2396-2408

[21] Lao, R-R., Tamg, J-H., and Hsiao, C.: 'Transmission coefficients measurement of building materials for UWB systems in 3-10 GHz'. Proc. IEEE Vehicular Technol. Conf. Spring April 2003, pp. 11-14

[22] Win, M. Z., and Scholtz, R. A.: 'On the robustness of ultra-wide bandwidth signals in dense multipath environments', IEEE Communications Letters, 1998, 2, (2), pp. 51-53

[23] A. Flatman: In-premises optical fibre installed base analysis to 2007, presented at the IEEE $802.310 G b E$ over FDDI Grade Fibre Study Group, Orlando, FL, Mar. 2004. 
[24] I. Gasulla and J. Capmany: 1Tb/s.km WDM transmission over multimode fibre link, $34^{\text {th }}$ European Conference on Optical Communication, ECOC 2008, paper Tu.3.E.5, vol.2, pp. 125-126, Sept. 2008.

[25] L. Raddatz and I. H. White,'Overcoming the Modal Bandwidth Limitation of Multimode Fiber by Using Passband Modulation” IEEE Photonics Technology Letters, Vol. 11, No. 2, 266-268, Feb.1999.

[26] P. Hartmann, X. Qian, A. Wonfor, R. Penty, and I. White, "1-20 GHz directly modulated radio overMMF link," in Proc. Int. Topical Meeting Microwave Photonics (MWP'05), Seoul, Korea, pp. 95-98, Oct. 2005.

[27] A.M.J. Koonen, A. Ng'Oma, H.P.B.A. van den Boom, I. Tafur Monroy and G.D. Khoe: New techniques for extending the capabilities of multimode fibre Networks, in Proc. of NOC, pp. 204-211, 2003.

[28] S. Kanprachar and I. Jacobs: Diversity of coding for subcarrier multiplexing on multimode fibres, IEEE Trans. Commun., vol. 51, pp. 1546-1553, 2003.

[29] I. Gasulla and J. Capmany: Transfer function of multimode fibre links using an electric field propagation model: Application to Radio over Fibre Systems, Opt. Express, vol. 14(20), pp. 9051-9070, Sept. 2006.

[30] H. Al-Raweshidy et al., "Radio over Fiber Technologies for Mobile Communication Networks", Artech House, 2002

[31] M. Sauer et al., "Radio Over Fiber for Picocellular Network Architectures”, J. Lightwave Technol., Vol. 25, No. 11 , pp. 3301-3320, 2007

[32] N. Gomes at al. "Radio-Over-MMF Techniques-Part I: RF to Microwave Frequency Systems", J. Lightwave Technol., Vol. 26, No. 15, pp. 2388-2395, 2008

[33] A. Kobyakov, J. George, and M. Sauer, "Study of system dynamic range for WLAN radio signal transmission over MMF and coax cable systems," in Proc. Int. Top. Meeting MWP, Grenoble, France, 2006 , pp. 1-4. P113.

[34] I. Möllers, D. Jäger, “Transparent Radio-over-Multimode Fiber Transmission System with Novel Transceiver for Picocellular Infrastructures", $35^{\text {th }}$ European Conference and Exhibition on Optical Communications (ECOC '09), September 20-24, Vienna, Austria, 2009 (accepted)

[35] Beltrán, M., Morant, M., Perez, J., and Llorente, R.: 'Performance Evaluation of OFDM and Impulse-Radio Ultra-Wideband over Fiber Distribution for In-Building Networks'. Proc. IEEE International Conference on Ultra-Wideband, Vancouver, Canada, September 2009

[36] G. Rajan, Y. Semenova, P. Wang and G. Farrell: Temperature-Induced Inestabilities in Macro-Bend Fibre Based Wavelength Measurement Systems, J. Lightwave Technol., Vol. 27, No. 10, pp. 1355-1361, 2009. 
[37] F. Tarrach, A. Ch'hayder and S. Guermazi: Influence of thermal aging on optical fibre properties, Opt. Eng., vol. 47(6), 065006(1-4), Jun. 2008.

[38] J. Montalvo, C. Vázquez, and D. S. Montero, "CWDM self-referencing sensor network based on ring resonators in reflective configuration," Opt. Express 14, n.11, 4601-4610, 2006

[39] D.S. Montero, I. Gasulla, I. Möllers, D. Jäger, J. Capmany and C. Vázquez "Experimental analysis of temperature dependence in multimode optical fiber links for Radio-over-Fiber applications" $11^{\text {th }}$ International Conference on Transparent Optical Networks ICTON 2009, July 2009. 
Table 1: Cost-performance comparison of coax, SMF, MMF and perfluorinated (PF) GRIN POF radio links (scenario: DAS with three $200 \mathrm{~m} 2.4 \mathrm{GHz}$ links, three BSs and one CS)

\begin{tabular}{|c|c|c|c|c|}
\hline Issue & Coax & SMF (glass) & MMF (glass) & POF (PF-GRIN) \\
\hline $\begin{array}{l}\text { Installation } \\
\text { effort }\end{array}$ & $\begin{array}{l}\text { High (EMV } \\
\text { restrictions -> } \\
\text { separation from } \\
\text { power lines, rel. thick } \\
\text { cable diameter) }\end{array}$ & $\begin{array}{l}\text { High (due to splicing } \\
\text { and fibre bending } \\
\text { restrictions ) }\end{array}$ & $\begin{array}{l}\text { Medium (needs } \\
\text { splicing, but higher } \\
\text { coupling efficiency) }\end{array}$ & $\begin{array}{l}\text { Medium-Low (no } \\
\text { complex splicing } \\
\text { techniques needed, } \\
\text { high coupling } \\
\text { efficiency) }\end{array}$ \\
\hline $\begin{array}{l}\text { CAPEX } \\
\text { (estimated) }\end{array}$ & $\begin{array}{l}\text { Cable: high quality } \\
\text { coax LMR-400 } \\
4 € / m \\
\text { Hubs: 3x } 1000 € \\
\text { Central Hub: } 1200 € \\
\text { Amplifier: 3x } 200 € \\
\text { Installation: } 4500 € \\
\text { Sum: } \mathbf{1 1 7 0 0 €}\end{array}$ & $\begin{array}{l}\text { SMF } 0.8 € / m \\
\text { Central Hub (3x OE } \\
\text { and 3x EO } \\
\text { components): } 4000 € \\
\text { Base Stations (each } \\
\text { 1x OE and } 1 x \text { EO } \\
\text { component): } 3 x \\
\text { 1500€ } \\
\text { Installation: } 6000 € \\
\text { Sum: } \sim \mathbf{1 5 0 0 0 €}\end{array}$ & $\begin{array}{l}\text { MMF } 0.7 € / \mathrm{m} \\
\text { Central Hub (3x OE } \\
\text { and } 3 x \text { EO } \\
\text { components): } 2000 € \\
\text { Base Stations (each } \\
1 x \text { OE and } 1 x \text { EO } \\
\text { component): } 3 x \\
\text { 1000€ } \\
\text { Installation: } 3000 € \\
\text { Sum: } \sim 8500 €\end{array}$ & $\begin{array}{l}\text { MMF } 1.5 € / m \\
\text { Central Hub (3x OE } \\
\text { and } 3 x \text { EO } \\
\text { components): } 2000 € \\
\text { Base Stations (each } \\
1 x \text { OE and } 1 x \text { EO } \\
\text { component): } 3 x \\
\text { 1000€ } \\
\text { Installation: } 2000 € \\
\text { Sum: } \sim 8000 €\end{array}$ \\
\hline $\begin{array}{l}\text { System } \\
\text { Dynamic } \\
\text { Range (SDR) } \\
@ 5.8 \mathrm{GHz}\end{array}$ & $\begin{array}{l}\text { 70-45 dB from } \mathbf{0} \text { - } \\
\text { 200m (passive) } \\
\text { lengths with high } \\
\text { quality coax cable, } \\
\text { below 20dB after } \\
>330 \mathrm{~m} \text { [33] }\end{array}$ & $60 \mathrm{~dB}$ over $>10 \mathrm{~km}$ & $\begin{array}{l}>45 \text { dB for } 0-500 m \\
{[33]}\end{array}$ & $>30 \mathrm{~dB}$ up to $100 \mathrm{~m}$ \\
\hline $\begin{array}{l}\text { Attenuation } \\
(\mathrm{dB} / \mathrm{km})\end{array}$ & $\begin{array}{l}1000 \mathrm{~dB} / \mathrm{km} \\
\text { (standard) - } 220 \\
\text { dB/km (high quality } \\
\text { coax LMR-400@ } \\
2.45 \mathrm{GHz})\end{array}$ & $\begin{array}{l}0.2 \mathrm{~dB} / \mathrm{km} @ \\
1550 \mathrm{~nm} \\
\text { Frequency } \\
\text { dependence } \\
\text { negligible }\end{array}$ & $\begin{array}{l}2.5 \mathrm{~dB} / \mathrm{km} @ 850 \mathrm{~nm} \\
5.4 \mathrm{~dB} / \mathrm{km} @ \\
2.4 \mathrm{GHz}\end{array}$ & $\begin{array}{l}>50 \mathrm{~dB} / \mathrm{km} @ \\
850 \mathrm{~nm} \\
\sim 30 \mathrm{~dB} / \mathrm{km} @ \\
2.4 \mathrm{GHz}\end{array}$ \\
\hline
\end{tabular}




\section{Figure Captions}

Fig. 1: Experimental setup for UWB RoF distribution for FTTH. Generated signal spectrum for: (a) OFDM-UWB, (b) IR-UWB.

Fig. 2: Performance comparison of OFDM and IR UWB RoF SMF distribution in terms of BER vs. received optical power for different FTTH SMF links.

Fig. 3: Experimental setup of the $60 \mathrm{GHz}$ UWB RoF.

Fig. 4: (a) Optical baseband monocycles at point (1), (b) RF spectrum of the UWB signal at $57 \mathrm{GHz}$ at point (2), (c) Eye diagram of demodulated monocycles at point (3) in Fig. 3.

Fig. 5: Planar view of proposed microring laser transmitter with added phase sections enabling multiwavelength operation.

Fig. 6: EVM calculations as a function of the modulation ratio for: (a) three MB-OFDM bands, i.e. bands 1, 7 and 13 , at $\lambda_{2}=1552.2 \mathrm{~nm}$ for different modulation ratios; and (b) MB-OFDM band 13 for three different wavelengths through phase tuning.

Fig. 7: a) Cloned transmitter array, b) Experimental $2 \times 2$ transmitter multiplicity advantage featuring additional $9 \mathrm{~dB}$ gain, c) Cloned receiver array, d) Experimental $2 \times 2$ receiver array featuring a further $13 \mathrm{~dB}$ gain, bringing overall link multiplicity advantage of $22 \mathrm{~dB}$ (c.f. theoretical gain of $24 \mathrm{~dB}$ ).

Fig. 8: Frequency response of MMF fibre link when considering: (a) MC or DMA effects, with $\alpha=2$ and for different fibre lengths, (b) different GRIN exponents, $\alpha$, when $L=2 \mathrm{~km}$, (c) different GRIN exponents, $\alpha$, when $L=3.05 \mathrm{~km}$.

Fig. 9: (a) transceiver schematic drawing (reflective modulator sensitive for $\lambda_{1}$, quasi-transparent for $\lambda_{2}$ ), (b) BS architecture for single fibre WDM MMF link in DAS.

Fig. 10: Experimental setup for RoMMF in-building UWB distribution.

Fig. 11: (a) OFDM-UWB generated signal spectrum and constellations, (b) IR-UWB generated monocycles time electrical spectrum and time signal, (c) Performance comparison of OFDM and IR UWB RoMMF distribution in terms of BER vs. optical power injected into the fibre (P3) and different launch power levels (P2).

Fig.12: (a) Experimental frequency response of the MMF fibre link at $\mathrm{T}=28^{\circ} \mathrm{C}$ and $\mathrm{T}=67^{\circ} \mathrm{C}$ for $L=3050 \mathrm{~m}$ and $\lambda=1300 \mathrm{~nm}$ with $\mathrm{Avg}=16$. (b) Measurement of the frequency response of an $L=3050 \mathrm{~m}$ MMF fibre link at $\lambda=1300 \mathrm{~nm}$ for a single sweep, (c) Hysteresis of the MMF link at the environmental temperature for a single sweep. (d) Averaged hysteresis of the MMF link at the environmental temperature.

Fwd: forwards; Bkw: backwards 


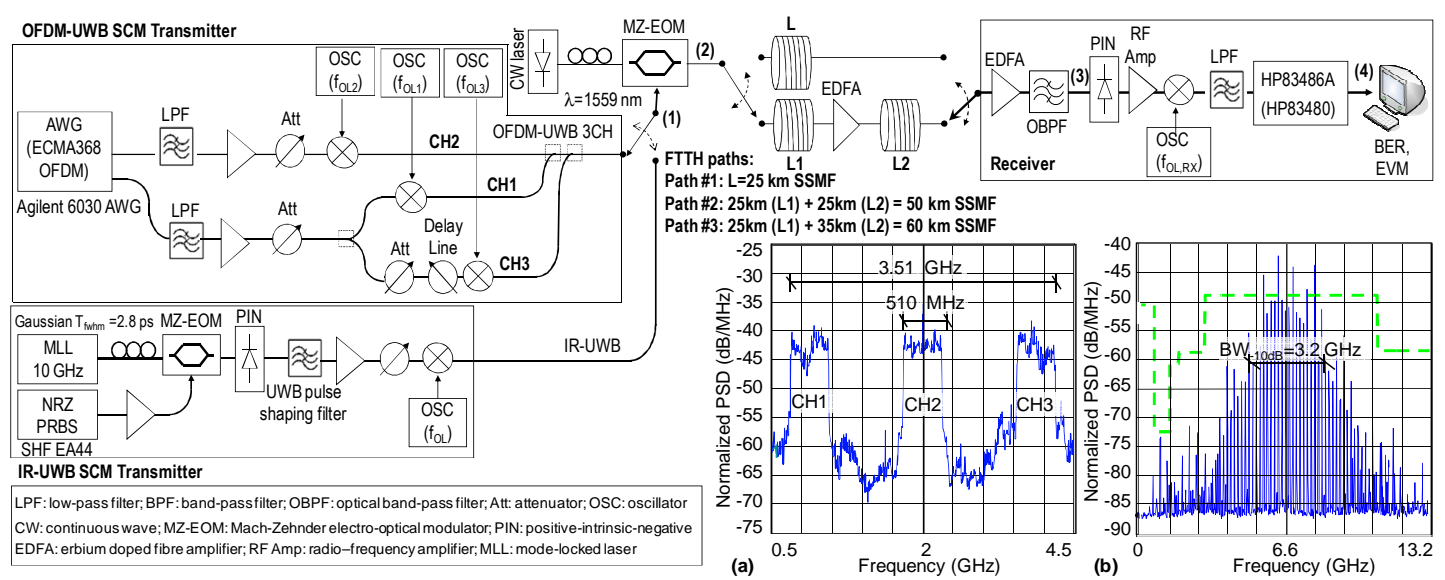

Figure 1: Experimental setup for UWB RoF distribution for FTTH. Generated signal spectrum for: (a) OFDM-UWB, (b) IR-UWB. 


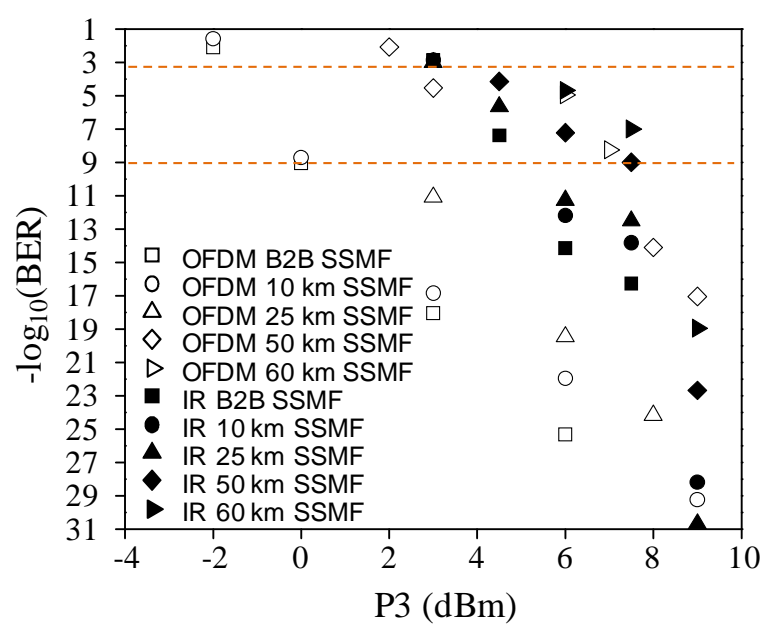

Figure 2: Performance comparison of OFDM and IR UWB RoF SMF distribution in terms of BER vs. received optical power for different FTTH SMF links. 


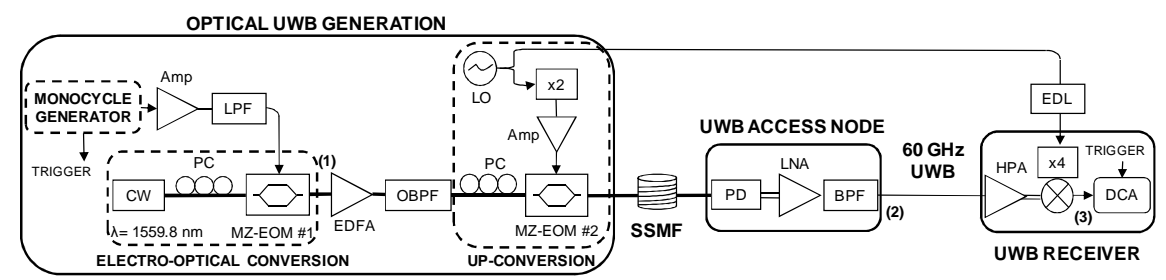

Fig. 3: Experimental setup of the $60 \mathrm{GHz}$ UWB RoF. 
(a)

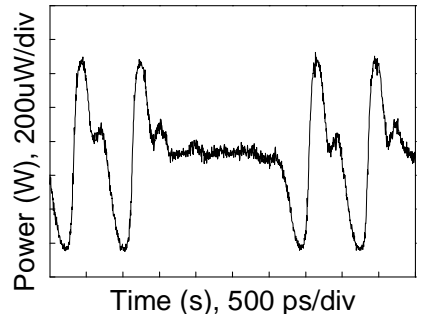

(b)

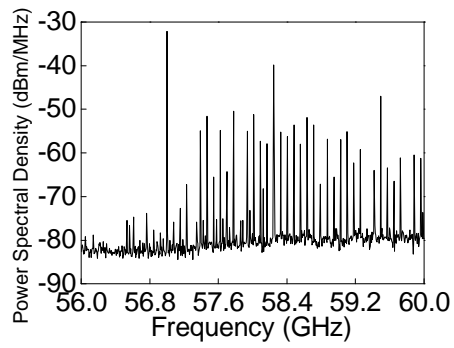

(c)

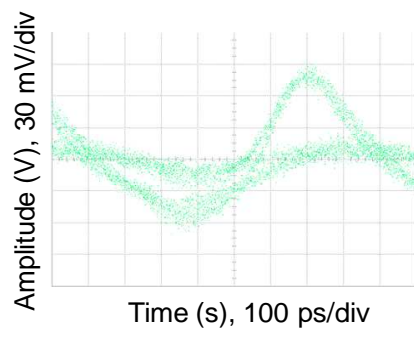

Fig. 4: (a) Optical baseband monocycles at point (1), (b) RF spectrum of the UWB signal at $57 \mathrm{GHz}$ at point (2), (c) Eye diagram of demodulated monocycles at point (3) in Fig. 3. 


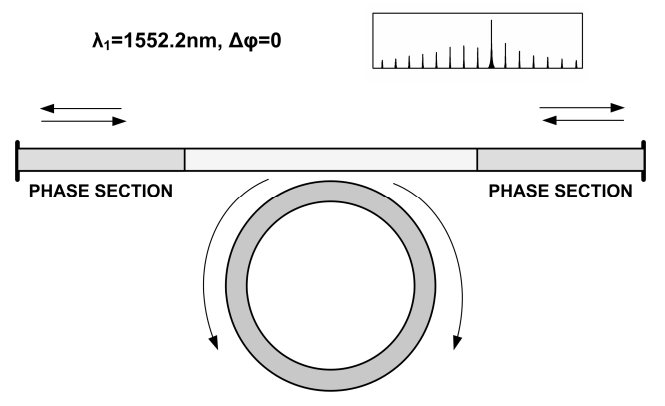

Fig. 5: Planar view of proposed microring laser transmitter with added phase sections enabling multiwavelength operation. 

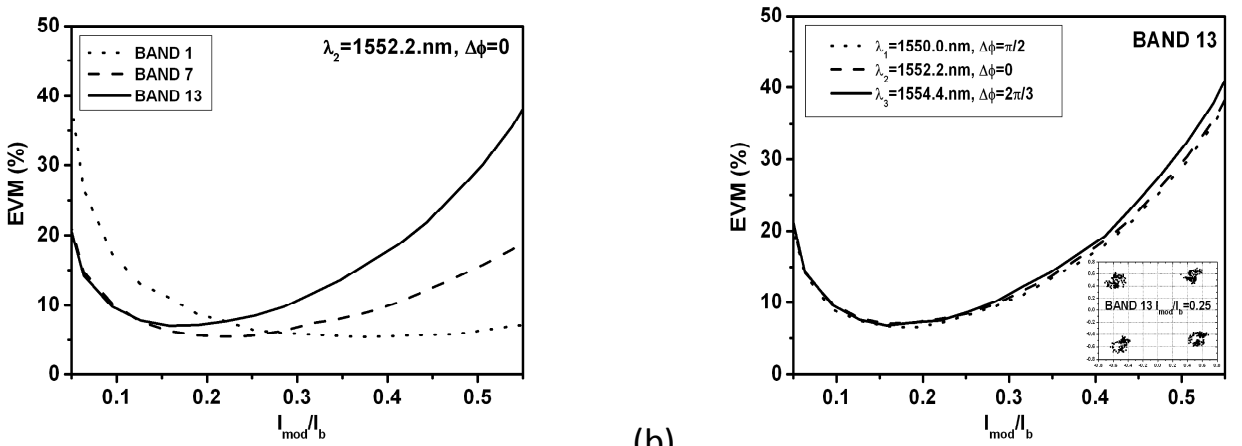

(a)

(b)

Fig. 6: EVM calculations as a function of the modulation ratio for: (a) three MB-OFDM bands, i.e. bands 1, 7 and 13, at $\lambda_{2}=1552.2 \mathrm{~nm}$ for different modulation ratios; and (b) MB-OFDM band 13 for three different wavelengths through phase tuning. 
Tx

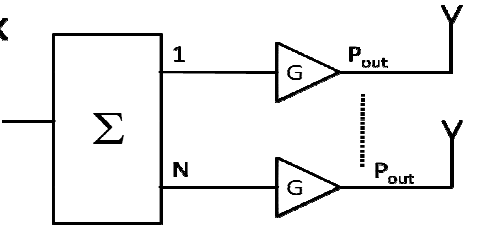

(a)

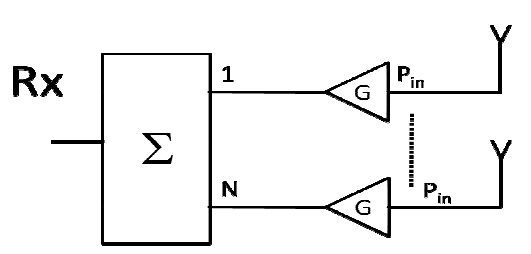

(c)

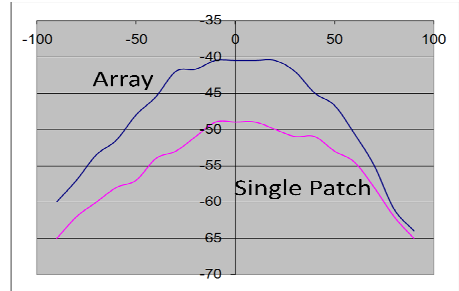

(b)

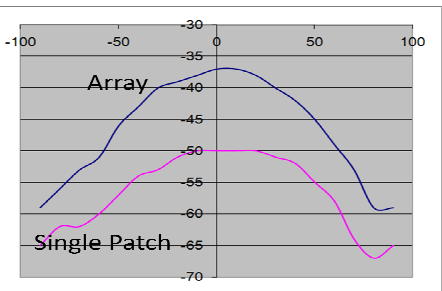

(d)

Fig. 7: a) Cloned transmitter array, b) Experimental $2 \times 2$ transmitter multiplicity advantage featuring additional $9 \mathrm{~dB}$ gain, c) Cloned receiver array, d) Experimental $2 \times 2$ receiver array featuring a further $13 \mathrm{~dB}$ gain, bringing overall link multiplicity advantage of $22 \mathrm{~dB}$ (c.f. theoretical gain of $24 \mathrm{~dB}$ ). 


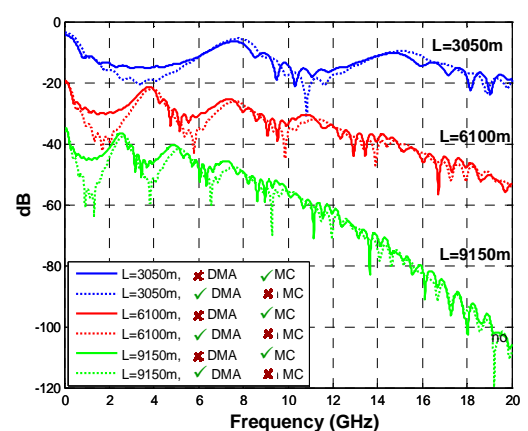

(a)

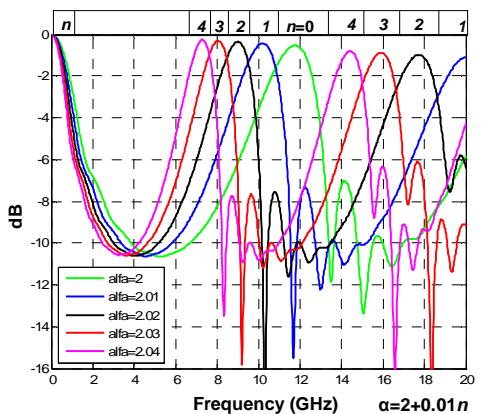

(b)

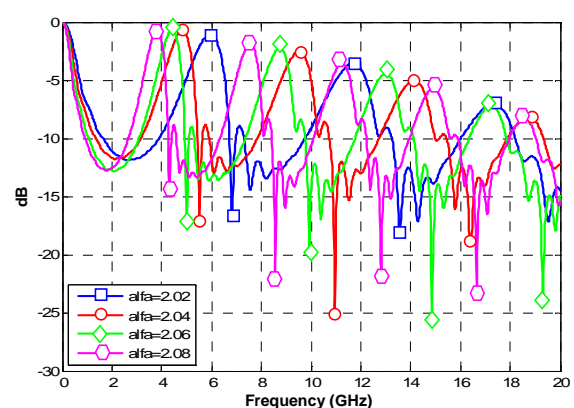

(c)

Fig. 8: Frequency response of MMF fibre link when considering: (a) MC or DMA effects, with $\alpha=2$ and for different fibre lengths, (b) different GRIN exponents, $\alpha$, when $L=2 \mathrm{~km}$, (c) different GRIN exponents, $\alpha$, when $L=3.05 \mathrm{~km}$. 

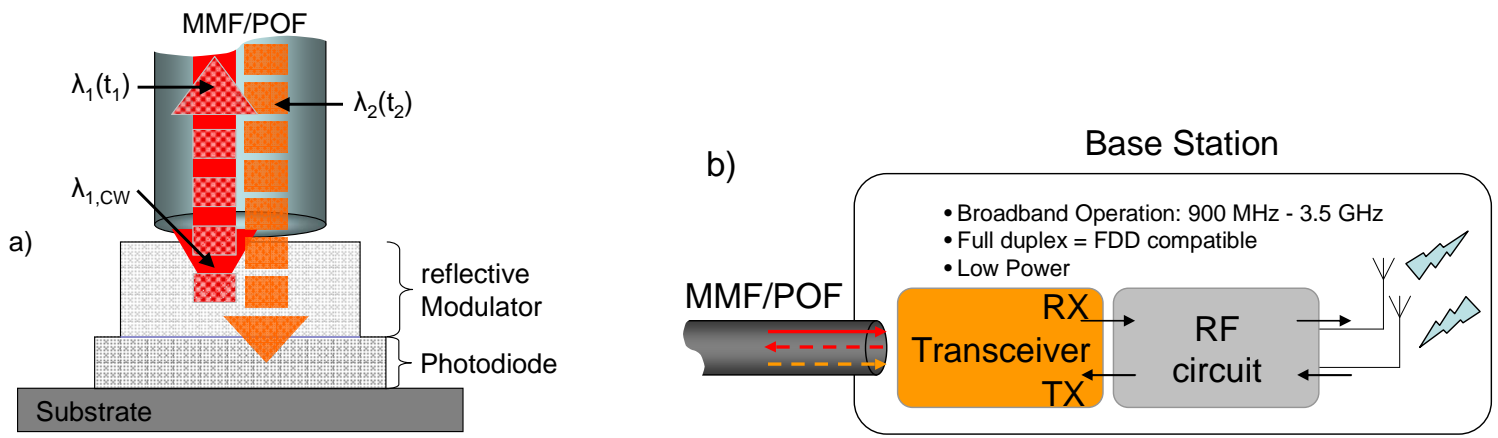

Fig. 9: (a) transceiver schematic drawing (reflective modulator sensitive for $\lambda_{1}$, quasi-transparent for $\lambda_{2}$ ), (b) BS architecture for single fibre WDM MMF link in DAS. 


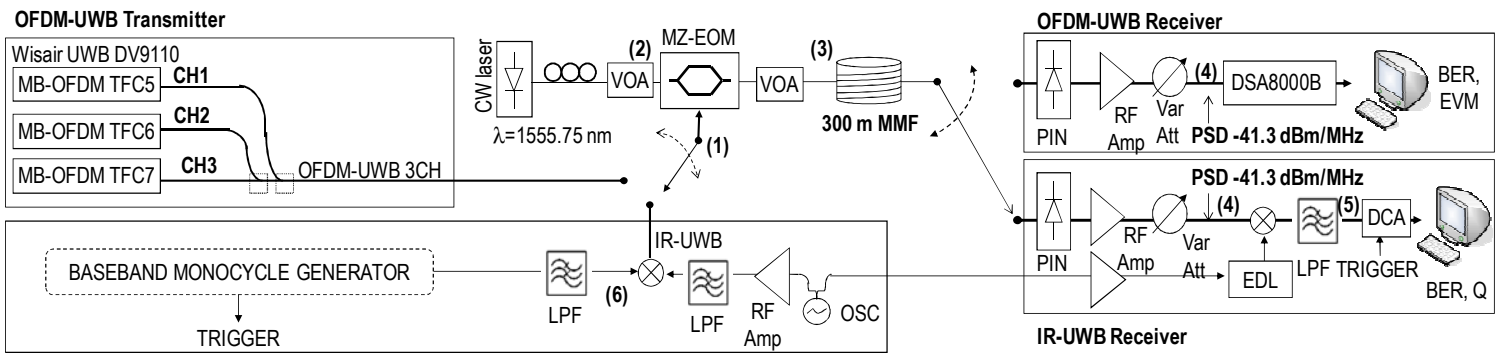

IR-UWB Transmitter

Fig. 10: Experimental setup for RoMMF in-building UWB distribution. 

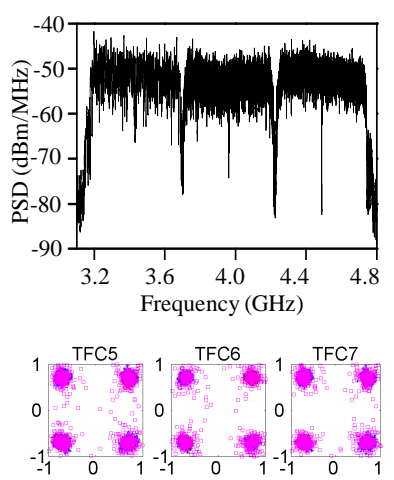

(a)
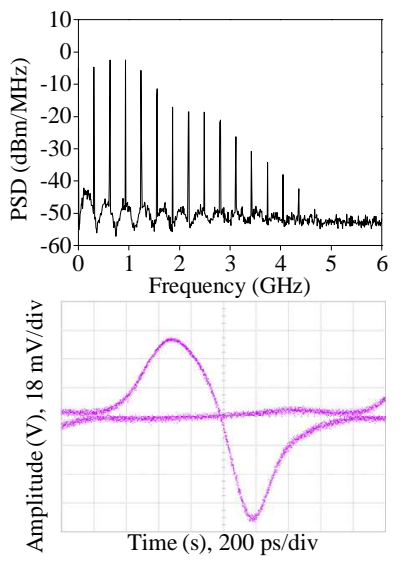

(b)

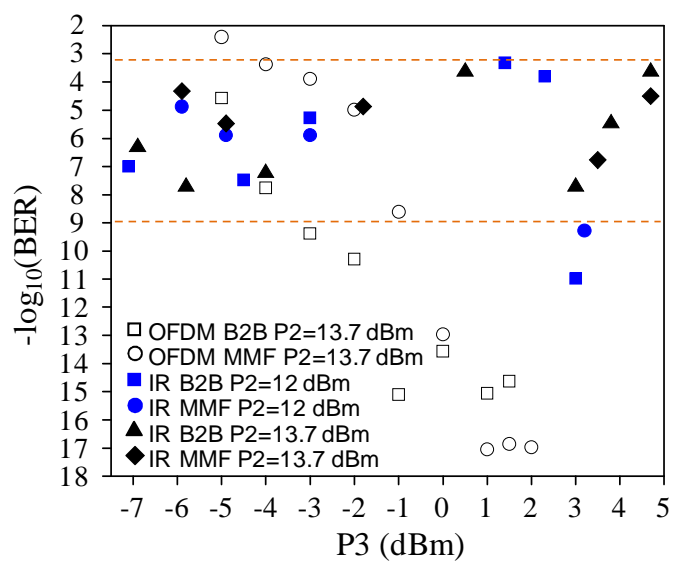

(c)

Fig. 11: (a) OFDM-UWB generated signal spectrum and constellations, (b) IR-UWB generated monocycles time electrical spectrum and time signal, (c) Performance comparison of OFDM and IR UWB RoMMF distribution in terms of BER vs. optical power injected into the fibre (P3) and different launch power levels (P2). 
(a)

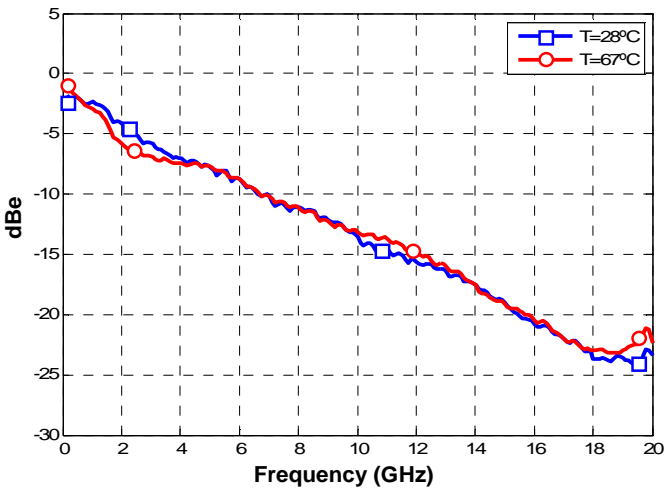

(c)

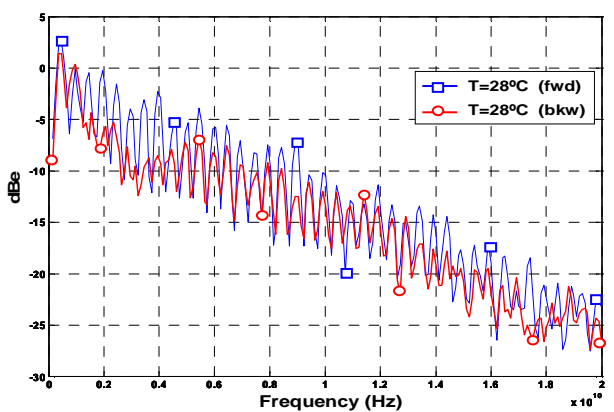

(b)

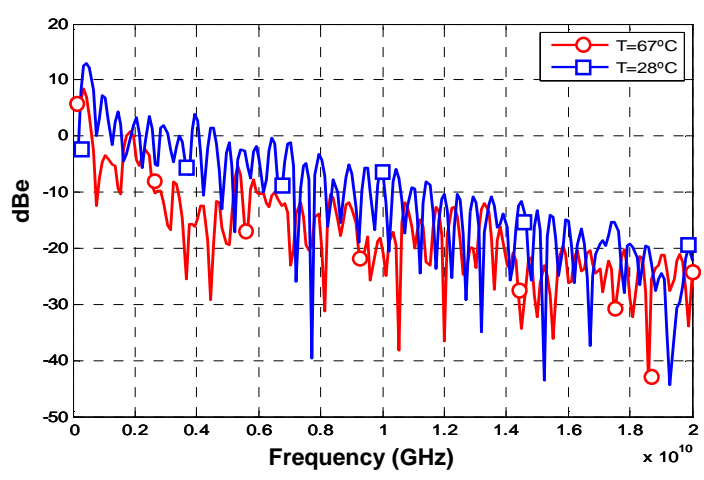

(d)

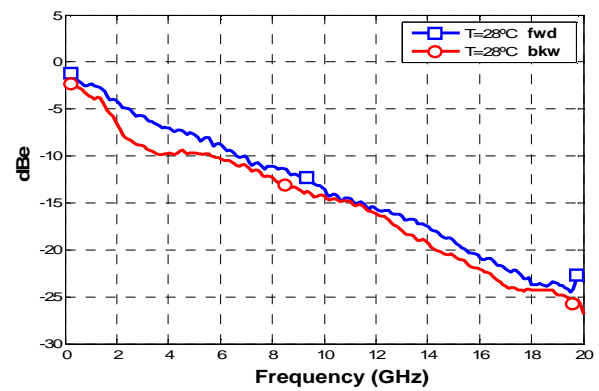

Fig.12: (a) Experimental frequency response of the MMF fibre link at $\mathrm{T}=28^{\circ} \mathrm{C}$ and $\mathrm{T}=67^{\circ} \mathrm{C}$ for $L=3050 \mathrm{~m}$ and $\lambda=1300 \mathrm{~nm}$ with $A v g=16$. (b) Measurement of the frequency response of an $L=3050 \mathrm{~m}$ MMF fibre link at $\lambda=1300 \mathrm{~nm}$ for a single sweep, (c) Hysteresis of the MMF link at the environmental temperature for a single sweep. (d) Averaged hysteresis of the MMF link at the environmental temperature.

Fwd: forwards; Bkw: backwards 